\title{
Mencari Media Pemanas Autoclave yang Murah dan Bersih
}

\author{
Lies Winarsih ${ }^{1 *}$, Aprira ${ }^{1}$, Dedi Susanto ${ }^{1}$, Edwar $^{1}$ \\ 'Laboratorium biologi sub lab mikrobiologi prodi Biologi fakuktas MIPA Universitas \\ Bengkulu. *E-mail l.winarsih@gmail.com
}

Submisi: 25 November 2020; Penerimaan: 24 Desember 2020

\begin{abstract}
ABSTRAK
Praktikum dan penelitian di laboratorium mikrobiologi menggunakan alat autoklaf. Alat ini berguna untuk mensterilkan alat dan bahan dengan menggunakan metode basah. Dalam pengoperasian autoklaf menggunakan air sebagai media pemanas. Pada penggunaan air sumur dan air galon isi ulang, sering terjadi endapan yang berwarna kecoklatan pada dasar autoclave setelah pemakaian dalam waktu tertentu. Juga menggunakan akuades dari laboratorium biologi, tetapi ketersediaan aquades terbatas dan membutuhkan biaya lebih. Untuk itu perlu dilakukan penelitian menggunakan beberapa macam jenis air/media sehingga didapat air/media yang murah, dan bersih untuk pengisian autoklaf. Penelitian ini bertujuan untuk mengetahui jenis air/media yang dapat digunakan dalam jangka panjang dengan mempertahankan kualitas sterilisasi, serta menjaga kebersihan autoklaf dan meminimalkan biaya. Penelitian dilakukan dengan melakukan percobaan di laboratorium dengan alat autoklaf dan air sumur, air galon isi ulang, akuades dan air sisa buangan AC sebagai pengisi autoklaf. Hasil penelitian menunjukkan bahwa penggunaan air sumur dan air galon isi ulang lebih cepat mengalami kekeruhan dibanding dengan aquades dan air sisa buangan AC dengan tingkat kekeruhan air sumur 46,8 NTU, air isi ulang 22,7 NTU, air aquades 8,72 NTU, dan air sisa buangan AC 3,5 NTU.
\end{abstract}

Kata Kunci : Autolave, media pemanas

\begin{abstract}
Practicum and research in microbiology laboratories used an autoclave. This tool was used to sterilize equipments and materials using wet method. An autoclave used water as a heater. In using of well water and refill mineral water, it was usually found brown sediment at the bottom of autoclave after the used of it in certain time. Besides, it used distilled water in biological laboratories but the availability of distilled water was limited and it was needed more cost. Thus, it was necessary to conduct a research that used several types of water or media in order to found the cheapness and cleanliness of water or media to fulfill an autoclave. The purpose of this research were to determine long term water or media to maintain the sterilization quality, maintain the cleanliness of an autoclave, and cost minimization. This research was conduct an experiment in laboratory that used an autoclave and the used of well water, refill water, distilled water, and air conditioner waste water. The results of this research were the level of turbidity after the used of well water was 46.8 NTU, refill water was 22.7 NTU, distilled water was 8.72 NTU, and air conditioner waste water was 3.5 NTU.

Keywords: Autolave, heating media
\end{abstract}

\section{PENDAHULUAN}

Laboratorium mikrobiologi sebagai salah satu sub laboratorium di laboratorium FMIPA Universias
Bengkulu, memiliki aktivitas yang cukup padat baik kegiatan praktikum maupun penelitian. Kegiatan praktikum meliputi 
praktikum mikrobiologi, mikologi dan kultur jaringan, dan kegiatan penelitian, meliputi penelitian mahasiswa dari program studi biologi, Fakultas Kedokteran, FKIP, program studi S2 IPA dan penelitian dosen. Kegiatan praktikum dan penelitian di laboratorium mikrobiologi tidak terlepas dari penggunaan alat dan bahan dengan alat autoklaf sebagai salah satu alat utama yang selalu digunakan.

Autoklaf merupakan salah satu alat yang sangat penting dalam praktikum dan penelitian di laboratorium mikrobiologi. Autoklaf di laboratorium mikrobiologi berjumlah tiga buah dengan spesifikasi 60 liter berjumlah dua buah dan 30 liter berjumlah satu buah. Autoklaf adalah alat pemanas tertutup yang digunakan untuk mensterilisasi suatu benda menggunakan uap bersuhu tinggi dan bertekanan tinggi ( Esmiyati, dkk (2012) Kondisi yang baik yang digunakan untuk sterilisasi adalah pada temperatur $121^{\circ} \mathrm{C}, 15$ psi selama kurang lebih 15 menit. Agar penggunaan autoklaf efektif dan uap air dapat menembus setiap alat yang disterilkan, autoklaf tidak boleh terlalu penuh agar uap air benar benar menembus semua area.( Adji, D, Larashanty H, dan Zuliyanti, 2017)

Selama ini untuk pengisi autoklaf sebagai media pemanas digunakan air kran dari sumur di laboratorium biologi Basic Science FMIPA UNIB, setelah beberapa kali pemakaian di dasar autoklaf terlihat kotor demikian juga ketika menggunakan air isi ulang, dan jika menggunakan akuades dari Laboratorium Biologi terlihat lebih bersih tetapi memerlukan banyak biaya.

Berdasarkan latar belakang di atas peneliti merumuskan permasalahan jenis air atau media pemanas apakah yang dapat digunakan untuk pengisian autoklaf yang lebih efektif dan efisien baik dalam hal biaya dan dalam perawatan alat sehingga alat autoklaf lebih bersih, efisien dan tahan lama.

Penelitin ini bertujuan untuk mengetahui dan mencari jenis air apa yang digunakan sebagai pengisi atau media pemanas autoklaf yang efektif, murah dan bersih.

\section{METODOLOGI}

\section{Waktu dan Tempat penelitian}

Penelitian ini dilaksanakan pada bulan juli sampai dengan bulan Oktober 2019 di Laboratorium Mikrobiologi FMIPA Universitas Bengkulu.

\section{Alat dan Bahan Penelitian}

Alat yang digunakan dalam penelitian ini adalah autoklaf merk ALP model KT/40S No seri. 805022 , amplas besi halus 3000, Autoklaf berfungsii untuk mensterilkan alat yang terdiri dari sebuah bejana yang didalamnya ada kumparan /lilitan tembaga yang jika dialiri listrik akan menghasilkan panas. Pada bagian inilah sebagai tempat air untuk menghantarkan/media pemanas atau menghasilkan uap yang berfungsi untuk mensterilkan. Untuk pembatas air dan bahan yang disterilkan dilengkapi dengan angsa.Sedangkan amplas besi digunakan untuk membersihkan kerak dan karat pada angsa dan kumparan tembaga. Sementara bahan yang digunakan dalam penelitian ini adalah air sumur, air isi ulang, air akuades, dan air sisa buangan AC. Secara rinci bagian dari autoklaf dapat dilihat pada gambar 1dan gambar 2 berikut ini

Metode penelitian yang digunakan adalah metode deskriptif yaitu suatu metode yang berfungsi untuk mendiskripsikan atau memberi gambaran terhadap obyek yang diteliti ( Setyowati dan Jumadi 2016). Penelitian ini dilakukan dengan pengamatan langsung dan pengumpulan data dari sampel yang digunakan serta dilakukan 
perbandingan nilai yang diperoleh dari

masing masing sampel.

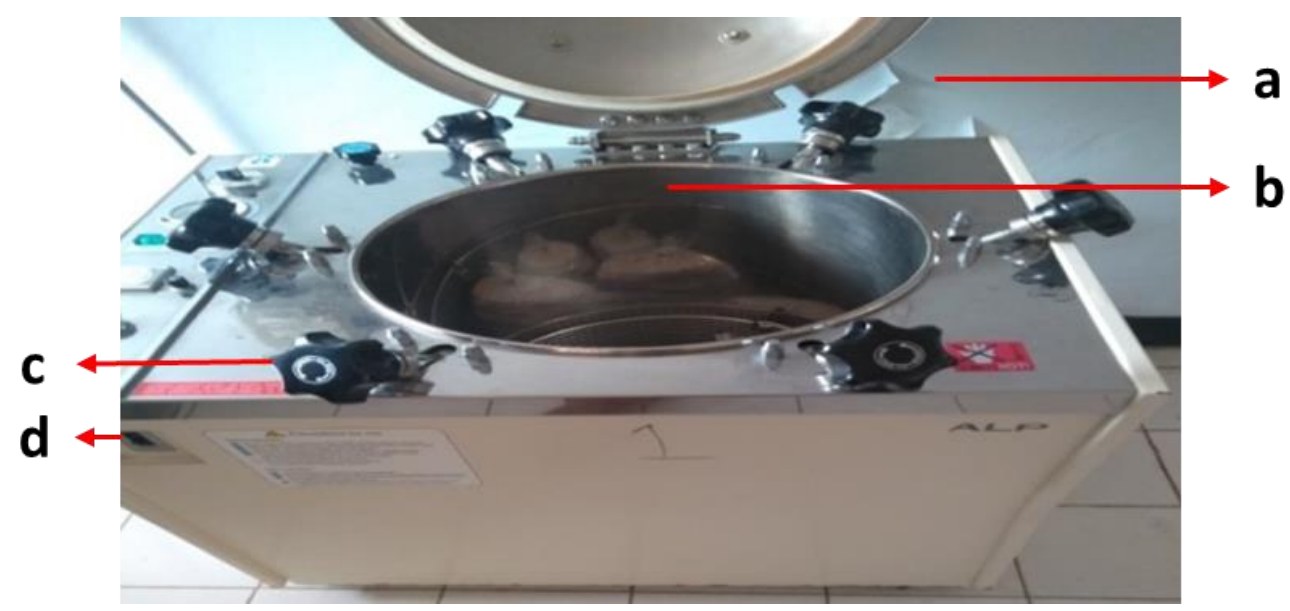

a. Tutup autoklaf

c. Katup pengaman

b. Bagian dalam autoklaf

d. Tombol power

Gambar 1 Foto alat di laboratorium mikrobiologi FMIPA UNIB

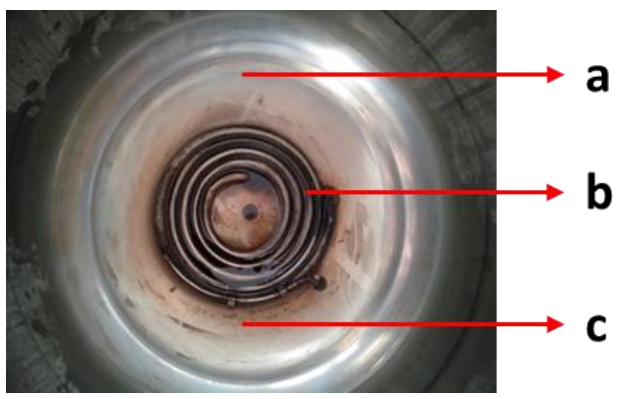

a.Tempat air/media pemanas

b.Kumparan baja

c.Bagian kotor sebelum dibersihkan

Gambar 2 bagian dalam autoklaf Foto alat di laboratorium mikrobiologi FMIPA UNIB

\section{Tahapan Penelitian}

Penelitian ini terdiri dari beberapa tahap antara lain pembersihan autoklaf terutama bagian dalam autoklaf dan saringan/angsa autoklaf dengan amplas halus, pengoperasian autoklaf dengan menggunakan air sumur, air isi ulang, air aquades, dan air sisa buangan $\mathrm{AC}$ sebagai pengisi autoklaf, dan dilakukan pengamatan secara visual serta tingkat kekeruhan setelah beberapa kali pemakaian. Tingkat kekeruhan diukur dengan Turbidimeter.

\section{Pembersihan Autoklaf}

Sebelum peralatan dipakai bagian dalam autoklaf dibersihkan dari kotoran dan kerak yang menempel dengan menggunakan amplas besi halus 3000 .

\section{Pengoperasian Alat}

Mengisikan air ke dalam autoklaf sampai batas yang ditentukan. Menutup autoklaf dan mengencangkan baut pengaman, menyalakan autoklaf dan mengatur timer minimal 15 menit di suhu 121 derajat celcius. Menunggu hingga air mendidih dan uap memenuhi semua kompartemen dan udara terdesak keluar, setelah itu kencangkan klep pengaman, tunggu hingga proses nya selesai, 15 menit dihitung setelah tekanan mencapai 2 atm. Setelah alarm berbunyi dan proses telah selesai, tunggu tekanan dalam kompartemen turun dan tekanannya sama dengan tekanan udara di luar, dan membuka baut pengaman. Mengulangi prosedur di atas sampai pemakaian kurang lebih 10- 20 kali, dan melakukan pengamatan setiap pemakaian hari ke 2,4,6 dst dengan menambahkan air jika telah berkurang, mengeluarkan air yang 
digunakan dan melakukan pemeriksaan kekeruhan. Mengulangi prosedur diatas dengan mengganti berturut turut air sumur, air isi ulang. Air aquades dan air sisa buangan AC.

\section{Pemeriksaan Kekeruhan}

Kekeruhan diperiksa dengan menggunakan alat turbidimeter. Dari keempat air yang digunakan sebagai media pemanas dikeluarkan dari autoklaf ditampung dengan derigen dan diukur kekeruhannya.

\section{HASIL DAN PEMBAHASAN}

\section{Hasil Pengamatan Secara Visual}

Setelah melakukan proses pemakaian autoklaf sebanyak $10-20$ kali dilakukan pengamatan secara langsung apakah terdapat perbedaan dengan penggunaan keempat air tersebut.

Tabel 1 Data Pengamatan Secara Visual

\begin{tabular}{llllllllll}
\hline Hari & 2 & 4 & 6 & 8 & 1 & 1 & 1 & 1 & 1 \\
ke & & & & & 0 & 2 & 4 & 6 & 8 \\
\hline Air & - & v & v & v & v & v & v & v & v \\
sum & & & & v & v & v & v & v & v \\
ur & & & & & & & & & \\
Isi & - & - & - & v & v & v & v & v & v \\
ulan & & & & & v & v & v & v & v \\
g & & & & & & & & & \\
aq & - & - & - & - & - & - & - & - & - \\
uad & & & & & & & & & \\
es & & & & & & & & \\
Sisa & - & - & - & - & - & - & - & - & - \\
AC & & & & & & & & \\
\hline
\end{tabular}

Keterangan ;

$v$ timbuk kekeruhan,

vv timbul kerak pada saringan,

(-) Tidak timbul kerak dan kekeruhan

Hasil analisis Kekeruhan

\begin{tabular}{cc}
\multicolumn{2}{c}{ Tabel 2 Data Uji Kekeruhan } \\
\hline Jenis air & Kekeruhan \\
\hline Air sumur & 46,80 \\
Air isi ulang & 22,70 \\
Air akuades & 8,72 \\
Air AC & 3,50 \\
\hline
\end{tabular}

Keterangan : pemeriksaan kekeruhan dilaksanakan pada akhir pemakaian dengan cara menguras alat.

$\begin{array}{llr}\text { Disamping } & \text { melakukan } \\ \text { pengamatan secara visual untuk }\end{array}$

mempertegas dilakukan pengujian kekeruhan dari keempat air yang digunakan setelah dipakai di autoklaf

\section{Pembahasan}

Dalam pengamatan secara visual dilakukan pengamatan setiap selesai running pertama, kedua dan seterusnya sampai running/pemakaian ke-10- 20 .Dari tabel (1) di atas menunjukkan pada pemakaian media pemanas dengan air sumur pada pemakaian running ke-4 sudah menunjukkan adanya kekeruhan, ini disebabkan karena kekeruhan dalam air dapat diakibatkan oleh bahan-bahan yang tersuspensi, bahan buangan industri, senyawa-senyawa organic ( Egy Asri Y U, Atiek M, Niken K (2016)). Pada hari ke -8 timbul kerak/karat pada saringan autoklaf dan pada hari selanjutnya timbul kerak semakin banyak, hal ini disebabkan air sumur mengandung kadarr besi yang tinggi (Riang Adeko (2018)). Pada pemakaian dengan air isi ulang pemakaian ke-8 mulai timbul kekeruhan dan pada ke-10 dan ke -12 kekeruhan semakin banyak namun tidak menimbulkan kerak atau karat, hal ini disebabkan masih adanya suspense atau kandungan mineral pada air yang tinggi tetapi kandungan besi $(\mathrm{Fe})$ yang rendah sehingga tidak menimbulkan karat. Untuk pemakaian dengan air akuades dan air sisa AC sampai pemakaian ke-10 tidak menimbulkan perubahan. Hal ini berarti pemakain air akuades dan air sisa buangan AC menunjukkan hasil yang lebih baik daripada pemakaian dengan air sumur dan air isi ulang.

Pada tabel 2 yaitu pada analisis kekeruhan menunjukkan bahwa kekeruhan yang paling kecil ditunjukkan pada pemakaian dengan air sisa pembuangan AC yaitu 3,5 NTU kemudian berturut turut yaitu air akuades 8,72 NTU, air galon isi ulang yaitu 22,7 NTU, dan paling besar ditunjukkan pada pemakaian air sumur yaitu 46,8 NTU. 
Lies Winarsih, Aprira, Dedi Susanto, Edwar/ Vol 3 (1) 2020, 34-38

\section{KESIMPULAN}

Dari hasil penelitian dapat disimpulkan sebagai berikut :

1. Penggunaan air sebagai media pemanas dalam pengoperasian autoklaf yang menunjukkan hasil paling kotor adalah dengan penggunaan air sumur, dan yang menunjukkan hasil paling bersih ditunjukkan dengan penggunaan air sisa pembuangan AC.

2. Dari data pengamatan secara visual, dan data kekeruhan dapat disimpulkan bahwa penggunaan air sebagai media pemanas dalam autoklaf yang paling afektif dan ekonomis dan murah adalah penggunaan air sisa buangan AC.

\section{UCAPAN TERIMAKASIH}

Terimakasih kepada semua pihak yang telah membantu pelaksanaan penelitian ini sampai selesai terutama kepada LPPM Universitas bengkulu dan FMIPA Universitas Bengkulu yang telah mendanai penelitian ini.

\section{DAFTAR PUSTAKA}

Adji, D, Larashanty, $\mathrm{H}$, dan Zuliyanti. 2007. Perbandingan Efektifitas Sterilisasi Alkohol 70\%, Inframerah, Autoklaf, dan Ozon terha.dap Pertumbuhan Bakteri Bacillus subtilis. Jurnal Sain ver.25(1) : halaman 18-26

Bambang Wahyudi Pratomo. 2018. Pemanfaatan Air Limbah AC sebagai Pengganti Akuades untuk analisis Serat Kasar Hijauan Pakan Dalam Menunjang Praktikum di Laboratorium Hijauan Makanan Ternak Dan Pastura fakultas Peternakan Prosiding Departemen TPHP FTP Universitas Gadjah Mada
Esmiyati Pembudidayaan Bandeng Juwana Berbasis Kearifan Lokal sebagai Muatan Lokal untuk Menumbuhkan Sikap Konservasi Siswa. Jurnal Sains Universitas Negeri semarang 1(1): Hal 21-25. 2012.

Egy Asri,Y, U, Atiek, M, dan Niken K. 2016.Resiko Kegagalan Pada Kualitas Air Minum Isi Ulang di Kecamatan Sukolilo Surabaya Menggunakan Faiture Mede And Effecct Analysis (FMEA) . Jurnal Teknik ITS vol 5 No 22016

Riang Adeko (2018) Pengaruh Cangkang Kopi Sebagai Adsorban Dalam Menurunkan Kadar Besi ( $\mathrm{Fe}$ ) Pada Sumur Galian JNPH Volume, 6 No 2 (Oktober 2018)

Setyowati, D, N, dan Junaidi, R. Analisis Roating Reservoir Dalam pengembangan Sumber Daya Air Kawasan Karst. AL-ARD Jurnal Teknik Lingkungan.2(1) (2016),p. 16-22 